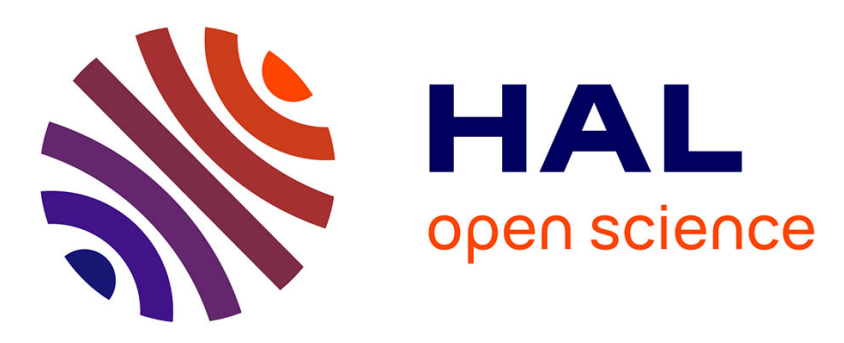

\title{
Interest of the minimum edit distance to detect behaviour change of the elderly person
}

\author{
Soumaya Msaad, Jean-Louis Dillenseger, Guy Carrault
}

\section{To cite this version:}

Soumaya Msaad, Jean-Louis Dillenseger, Guy Carrault. Interest of the minimum edit distance to detect behaviour change of the elderly person. 43rd Annual International Conference of the IEEE Engineering in Medicine and Biology Society (EMBC 2021), Oct 2021, Guadalajara, Mexico. 10.1109/EMBC46164.2021.9629665 . hal-03425499

\section{HAL Id: hal-03425499 \\ https://hal.science/hal-03425499}

Submitted on 10 Nov 2021

HAL is a multi-disciplinary open access archive for the deposit and dissemination of scientific research documents, whether they are published or not. The documents may come from teaching and research institutions in France or abroad, or from public or private research centers.
L'archive ouverte pluridisciplinaire HAL, est destinée au dépôt et à la diffusion de documents scientifiques de niveau recherche, publiés ou non, émanant des établissements d'enseignement et de recherche français ou étrangers, des laboratoires publics ou privés. 


\title{
Interest of the minimum edit distance to detect behaviour change of the elderly person
}

\author{
Soumaya Msaad, Jean-Louis Dillenseger and Guy Carrault
}

\begin{abstract}
In this article, a solution to detect the change of behaviour of the elderly person based on the person's activities of daily living is proposed. This work is based on the hypothesis that the person attaches importance to a rhythmic sequence of days and activities per day. The day of the elderly person is described by a succession of activities, and each activity is associated to a posture (lying down, sitting, standing, absent). Postures are estimated from image analysis measured by thermal or depth cameras in order to preserve the anonymity of the person. The change in posture succession is calculated using the minimum edit distance with respect to the routine day. The number of permutations/inversions reflects the change in the person's behaviour. The method was tested on two elderly persons recorded by thermal and depth cameras during 85 days in a retirement home. It is shown that for a person with a life change behaviour, the average number of permutations and interquartile range, before and after changes, are $41[28,48]$ and 57 [55-62] respectively compared to the learned routine day. The Wilcoxon test confirmed the significant difference between these two periods.

Clinical Relevance - Monitoring the daily routine provides indicators for detecting changes in the behaviour of an elderly person.
\end{abstract}

\section{INTRODUCTION}

The proportion of elderly people in Western countries is constantly increasing. In view of this situation, research is being conducted to improve the quality of life and increase autonomy. Among the proposed solutions, there are connected homes to ensure the safety of the elderly and allow them to preserve a maximum of autonomy. Emergency buttons, lighted pathways, appliance failure detectors, and fall sensors represent solutions to help aging well at home.

In the same time, different sensors have been proposed to monitor the elderly, to detect abnormal behaviour, and to intervene as quickly as possible by alerting health professionals or the family of the elderly person. Some work proposes wearable devices that automatically detect a fall and the positions (sitting, lying down, and standing) using sensors such as accelerometers [1], [2]. Indeed, falls are among the most critical anomalies that must be rapidly detected and treated in order to limit the potentially fatal consequences. However, these devices must be worn continuously, and the elderly person may not remember to wear it, for example after a shower. Other sensors can be found in smart homes such as passive infrared sensors [3], acoustic sensors [4], sensors placed in the ground [5], and traditional video

S. Msaad, J.-L. Dillenseger and G. Carrault are with Univ Rennes, Inserm, LTSI - UMR 1099, F-35000 Rennes, France.

soumaya.msaad@univ-rennes1.fr

jean-louis.dillensegereuniv-rennesl.fr

guy. carrault@univ-rennes1.fr sensors [6] or thermal [7] and depth sensors [8]. Constraints remain linked to the intrusive nature of the sensors and to the cost. In order to solve the cost and privacy issues, we have recently developed a solution based on low-cost depth and thermal sensors [9]. In a previous work, we demonstrated the interest in this approach to detect the fall [10]. In literature, it is reported that elderly person follows a well-defined routine in time, space, and social relationships [11]. In this contribution, we propose to evaluate the interest of the minimum edit distance in monitoring changes in the elderly person's routine.

The second section of this paper describes the proposed method. The third section presents the database and discusses the results the method yielded. The last section concludes this paper and indicates some additional directions for this work.

\section{Method}

The method for detecting changes in the behaviour is proposed on 4 steps as shown on Fig. 1.

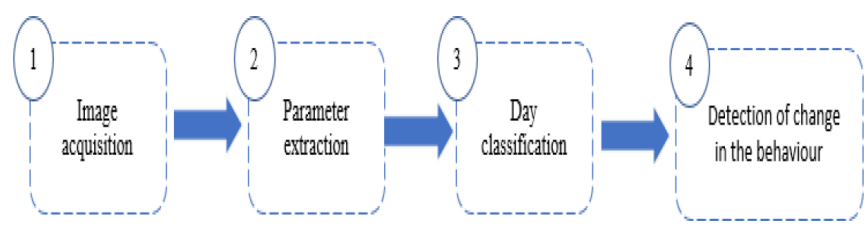

Fig. 1. Behaviour change detection framework.

A thermal sensor and a depth sensor (step 1) are placed in a room. For our experiment, it was two rooms in a retirement home for two dependent elderly people. Thermal and depth images, recorded every 15 minutes, provide information on the person's activity (sitting or lying down or standing) and potential falls as well as the person's absence. From the images, parameters are extracted (step 2) and then the images are classified with a machine learning algorithm (for our application we have selected the random forest algorithm) to detect falls, postures, and absence of the person (step 3). The day of the person is then described by the succession of postures with the indication of fall if it exists. After determining the daily routine, it is compared with the other recorded days using the minimum edit distance (MED) algorithm. This approach allows to measure the similarity between two sequences that can vary over time [12] and to quantify the number of transformations to change from one temporal sequence to another. The MED was found to be well suited to detect the change in the person's behaviour (step 4). 


\section{A. Detection of posture, fall, and absence of the person}

Each activity of the person is represented by a position. The following table I presents some examples of the activities and the position related to each activity.

TABLE I

ACTIVITIES AND POSITIONS

\begin{tabular}{|c|c|}
\hline Activities & Positions \\
\hline Sleeping & Lying down \\
\hline Cooking & Standing \\
\hline Having diner & Sitting \\
\hline Leaving the house & Absent \\
\hline Cleaning the house & Standing \\
\hline Reading on the sofa & Sitting \\
\hline Taking a shower & Absent \\
\hline sittings at his desk & Sitting \\
\hline Watching TV & Sitting \\
\hline Having a nap & Lying down \\
\hline
\end{tabular}

Fig. 2 and Fig. 3 illustrate some examples of images of person recorded respectively by a thermal and depth sensors.

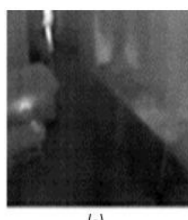

(a)

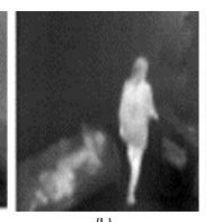

(b)

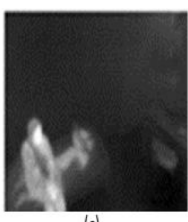

(c)

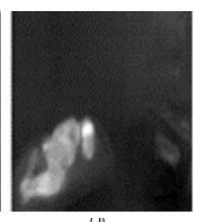

(d)
Fig. 2. Thermal images. a: The person is standing. b: The person is sitting on the bed. c: The person is lying down on the bed. $\mathrm{d}$ : The person is absent.

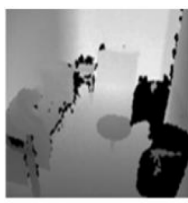

(a)

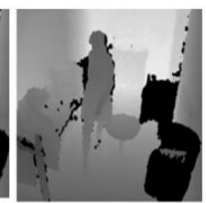

(b)

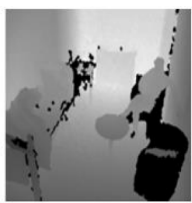

(c)

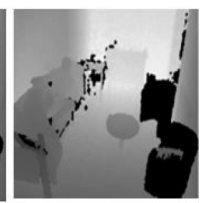

(d)
Fig. 3. Depth images. a: The person is standing. b: The person is sitting on the bed. c: The person is lying down on the bed. $\mathrm{d}$ : The person is absent.

These daily recordings therefore provide information on the person in his or her living environment, and the nonintrusive nature of the images.

In previous work [10], we were able to show that depth image processing allows us to estimate the following parameters: the floor plan, the visible proportion Near of the individual which lies under a predefined height $(30 \mathrm{~cm}$ for our experiment), the height of the centre of gravity $H \mathrm{cog}$, and the height Hhead of the head relative to the ground. These parameters can be used to classify the position of the person: lying down, sitting, standing, or if the person is absent. The presence or absence of the person is detected from the thermal images (the absence of hot spots in the thermal image indicates that the person is absent).

\section{B. Detection of behaviour change}

The principle of our study is based on the assumption that the person follows a well-defined daily routine in space, time, and social relationships [11]. The routine day must therefore be defined. In this work, it has been defined in two ways: 1) by asking the elderly person to describe their daily routine and then translate the succession of activities into a succession of postures, 2) by recording the person over several days and the routine day posture at a time $t$ corresponds to the most frequent posture over the recording period. If the elderly person is robust, the day routine is defined after recording the person for several days (for example 10 days). When the routine day is determined, the MED algorithm is applied and the number of transformations measured to switch from a recorded day to the routine day is computed.

As a brief reminder, minimum edit distance is inspired from the Levenshtein distance. MED is able to find the optimal global alignment between two sequences, i.e., to associate each element of each sequence to at least one element of the other sequence by minimizing the association costs. The cost of an association is the distance between the two elements.

Fig. 4 shows computation of the distances between each letter of the sequence $1(\mathrm{a}, \mathrm{b}, \mathrm{c}, \mathrm{d}, \mathrm{e}, \mathrm{k})$ with every letter of the sequence $2(\mathrm{a}, \mathrm{z}, \mathrm{c}, \mathrm{e}, \mathrm{d})$ and presents the optimal match between them.

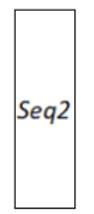

\begin{tabular}{|l|l|l|l|l|l|l|}
\hline$d$ & 4 & 4 & 3 & 2 & 3 & 3 \\
\hline$e$ & 3 & 3 & 2 & 2 & 2 & 3 \\
\hline$c$ & 2 & 2 & 1 & 2 & 3 & 4 \\
\hline$z$ & 1 & 1 & 2 & 3 & 4 & 5 \\
\hline$a$ & 0 & 1 & 2 & 3 & 4 & 5 \\
\hline & $a$ & $b$ & $c$ & $d$ & $e$ & $k$ \\
\hline
\end{tabular}

Seq1

Fig. 4. An example of using the minimum edit distance algorithm to switch from sequence 1 to sequence 2 .

The algorithm returns 3 necessary modifications to perform on sequence 1 in order to align it with sequence 2 . These are: i) to replace $b$ by $z$, ii) to delete $d$ and iii) to replace $\mathrm{k}$ by $\mathrm{d}$.

\section{RESUltS}

After a presentation of the two databases, we introduce in a first step the performances of postures, falls and absences detection of the person. In a second step, the results concerning the MED algorithm are presented. Finally, we analyze the evolution of the behavioural change detection results during our experiment.

\section{A. The database}

The databases consist of depth and thermal images recorded by the depth and thermal sensors installed in the rooms of two elderly people (person A and person B) in the Raymond Thomas retirement home in Rennes, France. The experimental procedure was approved by the ethical review board of the nursing home and seniors participating gave their consent and its signed agreement to take part. 
The images have been acquired every $15 \mathrm{~min}$. This sample frequency was considered appropriate to have a global view of the organization of the person's day. The database consisted of images recorded during 85 days. It consists of 8160 thermal images and 8160 depth images and the database was manually annotated. The persons recorded are dependent seniors with reduced mobility. Therefore, the duration of the person standing was short. In this case, the standing posture is almost never captured by the depth sensor.

\section{B. Posture and fall detection performance}

The Random Forest was used to classify the fall and the postures with a k-fold cross validation $(k=5)$ method. Referred to the whole database, we have typically measured an accuracy of about $95 \%$. We respectively obtained the following errors rates for fall, lying down and sitting classes: $11 \%, 3 \%$, and $7 \%$. When the person is absent, we also observed an accuracy of about $100 \%$ because in the thermal images there is no hot spot.

\section{Detection of behaviour change}

Fig.5 and Fig. 6 represents, respectively for person A and $\mathrm{B}$, the succession of the ground truth: sitting (blue), lying down (purple), absent (red), standing (white), or falling (yellow) during the day (y-axis) over 85 days (x-axis). Also, for each person the routine day is presented next to the database. The routine day is proposed after selecting the most frequent posture at a time $t$ of recording for the 60 first days.

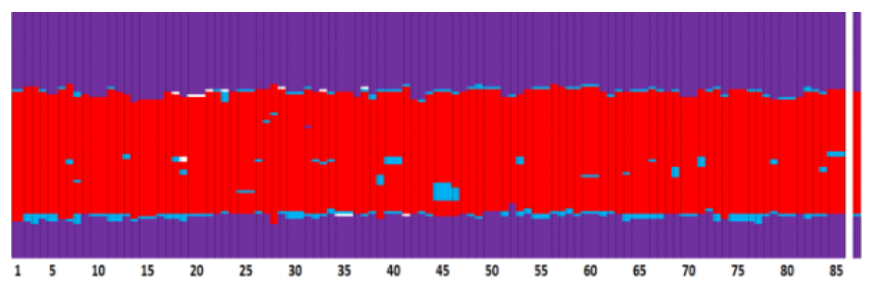

Fig. 5. Annotations of the images of the person A during the day (y-axis) over 85 days (x-axis). The vertical line on the right represents its routine day.

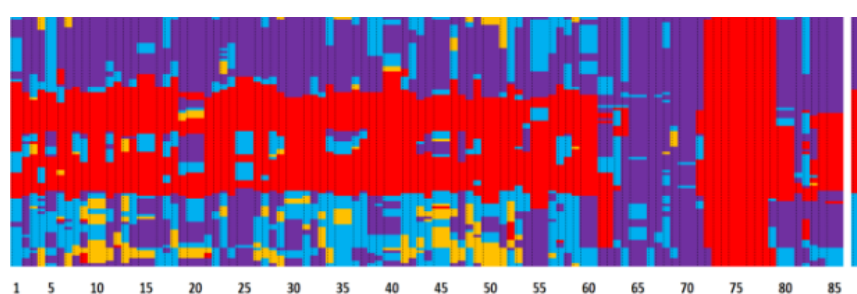

Fig. 6. Annotations of the images of the person B during the day (y-axis) over 85 days ( $\mathrm{x}$-axis). The vertical line on the right represents its routine day.

We notice that the behaviour of person $\mathrm{A}$ is almost stable with no falls. For person B (PB), we observe from the first day to the 62nd day that the person's day is described by three periods. The first period where PB is often lying down and sleeps. The second phase where PB is absent from his room, and the third period where $\mathrm{PB}$ returns to the room and is often sitting. This explains the proposal of the routine day for person B. After the 62nd day, PB does not leave the room during 7 days and is often lying down. Then PB is hospitalized during 8 days. Finally, PB comes back and retrieves progressively his routine day. A change in the behaviour of this person is then observed. Fig. 7 shows the result the number of MED transformations per day for person A and person B. Fig. 7 also shows with a continuous line the 7-day moving average of the number of MED transformations.

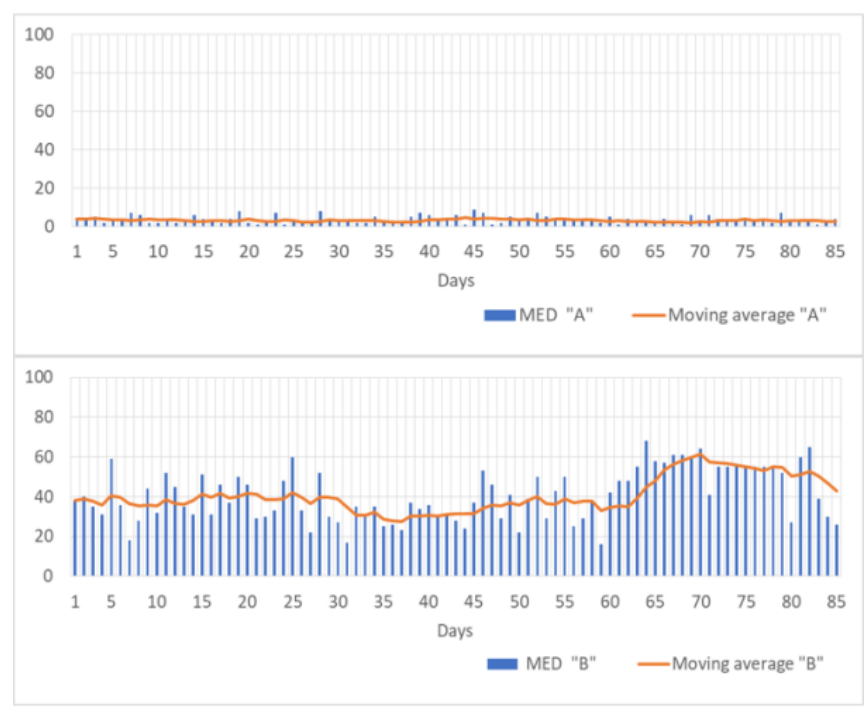

Fig. 7. Number of transformations between the routine day and the days recorded for person $\mathrm{A}$ and $\mathrm{B}$. The continuous line represents the 7-day moving average of the number of MED transformations.

These results show that the very regular life of person $\mathrm{A}$ is perfectly captured by the MED algorithm which shows few modifications. On the other hand, the analysis of the MED transformations for person B shows an increase in the number of transformations from day 63. We also notice after PB comes back to his room that the number of transformations progresses slowly to the first day values.

After having annotated the images and observed the ground truth for person $\mathrm{B}$, the database described by the results of the MED transformations was divided into 7 groups (A, B, C, D, E, F, and G) of homogeneous activities. Group $\mathrm{A}, \mathrm{B}, \mathrm{C}, \mathrm{D}$ correspond to day 1 to day 62 , group $\mathrm{E}$ to day 63 to 71 while groups $F$ and $G$ correspond to day 72 to 78 and 79 to 85 respectively. The number of transformations per group is depicted as boxplots Fig. 8.

Several remarks can be made:

- The number of transformations in groups A, B, C and, $\mathrm{D}$ are quite similar. This is explained by the fact that the person follows a routine on the total days of these groups.

- The median values of groups A, B, C, D are clearly different from groups $\mathrm{E}$ and $\mathrm{F}$. This is explained by the loss of routine during these days.

- The data from group $\mathrm{G}$ are the most dispersed. The common values of group $\mathrm{G}$ with the other groups is 


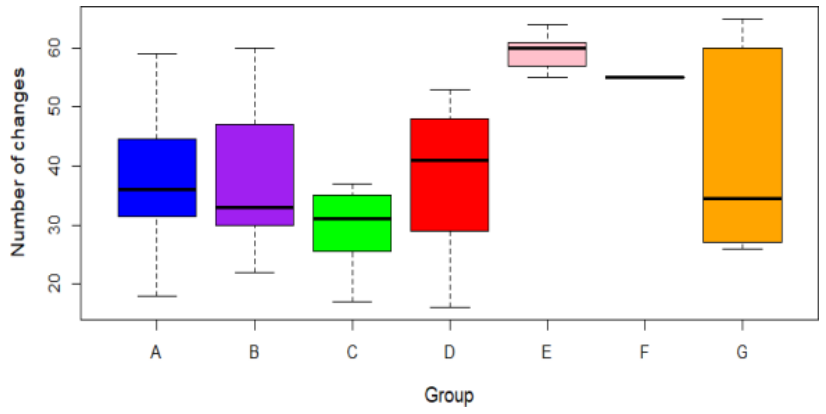

Fig. 8. Boxplot of the number of changes per group of days

explained by the fact that the person returns to his routine gradually after coming back from the hospital.

In order to identify the groups that are significantly different, we apply the Wilcoxon test pairwise of groups, the results are presented in Table II:

TABLE II

WILCOXON TEST RESULTS

\begin{tabular}{|c|c|c|c|c|c|c|}
\hline & $\mathrm{A}$ & $\mathrm{B}$ & $\mathrm{C}$ & $\mathrm{D}$ & $\mathrm{E}$ & $\mathrm{F}$ \\
\hline $\mathrm{B}$ & 0.87 & & & & & \\
\hline $\mathrm{C}$ & 0.061 & 0.176 & & & & \\
\hline $\mathrm{D}$ & 0.87 & 0.87 & 0.135 & & & \\
\hline $\mathrm{E}$ & 0.001 & 0.002 & 0 & 0.001 & & \\
\hline F & 0.001 & 0.002 & 0 & 0 & 0.273 & \\
\hline G & 0.952 & 1 & 0.362 & 0.87 & 0.187 & 0.421 \\
\hline
\end{tabular}

It can be seen that groups A, B, C, and D are not significantly different $(p>0.05)$. On the other hand, groups A, B, C and D have a statistically significant difference with groups $\mathrm{E}$ and $\mathrm{F}(p<0.05)$. There is no significant difference between group $\mathrm{G}$ and the other groups. This can be explained by the fact that group $G$ was described by days when the person gradually retrieved his routine.

By merging groups, A, B, C, D into the routine group RG and groups $E$ and $F$ into the non-routine group NRG and by denoting med [Q25th, Q75th] the median and the interquartile range of the number of MED transformations, we reached for RG 38 [28, 48] and for NRG 55 [55, 62]. These results show quasi no-overlap between the two groups and confirm the ability of the MED to perceive modifications in the daily routine of an elderly person.

\section{CONCLUSION}

In this article, we propose a solution to detect behaviour change of a person based on the comparison of each day with his routine day. The day is represented by a succession of postures (standing, lying down, sitting, and standing), the absences and falls. Postures, falls and absences of the person are detected by the depth and thermal sensors. The method was applied on two databases of two elderly person living in a nursing home over 85 days.

Minimum edit distance (MED) was applied for measuring similarity between the two temporal sequences: current ob- served day and routine day. We have shown that the MED is able to capture the loss of the routine.

This work is still under development, it represents the first steps to detect the change in the person's behaviour. We assume that these changes translate modifications in their health status. In the longer term, it is envisaged to design a clinical study over several months and for several seniors in order to progressively orient this work towards the monitoring of the frailty of the elderly. Its ultimate goal is to propose an index allowing the relatives or the doctor to follow the elderly person and his evolution. Indeed, early intervention following a change in the behaviour will make it possible to improve his health in case of deterioration or to propose new life solutions in case of improvement.

\section{ACKNOWLEDGMENT}

This work was part of the PRuDENCE project (ANR16-CE19-0015) which has been supported by the French National Research Agency (ANR). The first author received also a scholarship from the Brittany Council.

\section{REFERENCES}

[1] M. Abbas, D. Somme, and R. Le Bouquin Jeannès, "Machine learningbased physical activity tracking with a view to frailty analysis," in 42nd Ann Int Conf of the IEEE EMB (EMBC), 2020, pp. 3917-3920.

[2] M. Saleh and R. Le Bouquin Jeannès, "Elderly fall detection using wearable sensors: a low cost highly accurate algorithm," IEEE Sens $J$, vol. 19, no. 8, pp. 3156-3164, 2019.

[3] A. Sixsmith, N. Johnson, and R. Whatmore, "Pyroelectric IR sensor arrays for fall detection in the older population," $J$ Phys $I V$, vol. 128, pp. 153-160, 2005.

[4] Y. Li, Z. L. Zeng, M. Popescu, and K. C. Ho, "Acoustic fall detection using a circular microphone array," in 32nd Ann Int Conf of the IEEE $E M B(E M B C), 2010$.

[5] Y. Zigel, D. Litvak, and I. Gannot, "A method for automatic fall detection of elderly people using floor vibrations and sound-proof of concept on human mimicking doll falls," IEEE T Bio-med Eng, vol. 56 , no. 12 , pp. $2858-2867,2009$.

[6] E. Auvinet, F. Multon, A. Saint-Arnaud, J. Rousseau, and J. Meunier, "Fall detection with multiple cameras: an occlusion-resistant method based on 3-D silhouette vertical distribution," IEEE T Inf Tech Bio, vol. 15, no. 2, pp. 290-300, 2011.

[7] L. Tao, B. Volonakis, T.and Tan, YG Jing, K. Chetty, and M. Smith, "Home activity monitoring using low resolution infrared sensor," CoRR, vol. abs/1811.05416, Nov. 2018

[8] E. E. Stone and M. Skubic, "Fall detection in homes of older adults using the microsoft kinect," IEEE J Biomed Health Inform, vol. 19, no. 1, pp. 290-301, 2015.

[9] I. Halima, J.-M. Laferté, G. Cormier, A.-J. Fougères, and J.-L. Dillenseger, "Depth and thermal information fusion for head tracking using particle filter in a fall detection context," Integrated ComputerAided Engineering, vol. 27, no. 2, pp. 195-208, 2020.

[10] S. Msaad, G. Cormier, and G. Carrault, "Detecting falls and estimation of daily habits with depth images using machine learning algorithms," in 42nd Ann Int Conf of the IEEE EMB (EMBC), 2020.

[11] V. Bergua, J. Bouisson, J.-F. Dartigues, J. Swendsen, C. Fabrigoule, K. Pérès, and P. Barberger-Gateau, "Restriction in instrumental activities of daily living in older persons: association with preferences for routines and psychological vulnerability," Int J Aging Hum Dev, vol. 77, no. 4, pp. 309-329, 2013.

[12] S.-R. Kim and K. Park, "A dynamic edit distance table," Journal of Discrete Algorithms, vol. 2, no. 2, pp. 303-312, jun 2004 